Send your letters to the editor, British Dental Journal, 64 Wimpole Street, London W1G 8YS Email bdj@bda.org

Priority will be given to letters less than 500 words long. Authors must sign the letter, which may be edited for reasons of space

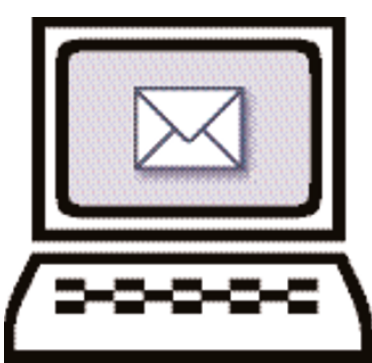

\section{Territorial disputes}

Sir, I read with interest Mr McArdle's comments (BDJ 2006; 200: 1) on $\mathrm{Mr}$ Wood's letter (BDJ 2006; 199: 249). Mr McArdle is a valued member of our team and is correct in his assertion that the OMFS registrars are not exposed to significant dento-alveolar surgery in this centre. This is because Guy's, King's College and St Thomas's (GKT) Hospitals house specialist cleft, head and neck cancer, and trauma services. But only one third of their training time is at GKT, two thirds are at peripheral hospitals where there is a significant exposure to dento-alveolar surgery.

Territorial disputes are undignified and counter productive particularly as market share depends ultimately on the quality of service provided. If there is concern regarding training, it can be quantified by reference to logbooks which should be in the public domain.

M. McGurk

By email

doi: $10.1038 /$ sj.bdj.4813378

\section{RITA outcomes}

Sir, I read with interest the letters to the editor on this subject (BDJ 2005; 199: 249 and $B D J$ 2006; 200: 2). I was concerned at the suggestion that OMFS trainees may be lacking in 'appropriate training and clinical experience in surgical dentistry'. I therefore reviewed our local pattern of RITA outcomes. In London, it is reassuring to note that for the past five years no RITA outcome indicates such a deficiency.

For information I would like to point out that the acronym RITA stands for 'Record of In-Training Assessment' and that from 1996 those in training programmes leading to CCST are Specialist Registrars not Registrars.

\section{E. Jones}

\section{London Deanery}

doi: 10.1038/sj.bdj.4813379

\section{Anecdotal data}

Sir, Mr McArdle's data are wrong, and so unfairly do great harm to the training and assessment process. It is also unacceptable to broadcast such disinformation about the trainees, who work so hard and show such dedication to fulfil the rigours of their long training programme.

As I have pointed out to him at RITAs in the past, OMFS SpRs are not obliged to present data on procedures once they get above a couple of hundred cases. So the current logbooks may not show certain categories, but closer inspection and inquiry would show the true extent.

On a general point, 'counting operations' is only one part of training; indications, ethics, communications, complications pre and post operative care etc, are of course equally important parts of training. Since, like most OMF units, all the consultants at the Queen Victoria Hospital personally undertake day case/local anaesthetic lists for minor oral surgery, there are always opportunities for trainees to gain more teaching in MOS.

Finally if he feels an individual is deficient in any aspect of his training, and this view is shared by the RITA panel, then his role is to offer targeted training to the individual. I understand he in fact approved all the trainees in question to continue (RITA C) training. Writing anecdotal, inaccurate letters seems less valuable to trainees.

In the hospital service we are used to close team working with surgeons who will form the bulk of the future oral surgery speciality. I do not think this type of letter is helpful, but I for one will continue working closely with my oral surgical colleagues as part of our team.

\section{P. Ward Booth}

President, British Association of Oral \&

Maxillofacial Surgeons

doi: 10.1038/sj.bdj.4813380

\section{Misinformation}

Sir, Mr McArdle's letter (BDJ 2006; 200: 2) regarding surgical dentistry training of oral and maxillofacial surgeons is inaccurate and misinforming. Most of the registrars have executed a prodigious number of dentoalveolar procedures over a period of 15-18 years of undergraduate and postgraduate training and indeed many were on the GDC's Surgical Dentistry specialist register even while training in oral and maxillofacial surgery (OMFS). $\mathrm{Mr}$ McArdle is not an oral and maxillofacial surgeon, nor is he a trainer for OMFS. He is on the Surgical Dentistry register. The training programme for OMFS is extensive and not part of his limited remit. He is wrong to state that RITA stands for Registrar in Training Assessment. It stands for Record of In-Training Assessment. The subtlety has escaped him, but sadly so has a lot else on this matter.

Regarding the issue of manpower planning for dentoalveolar services; most of the dentoalveolar surgery should be carried out by our GDP colleagues. It is a preposterous suggestion that the Department of Health should create and finance through the tax-payer another tier of consultants on the NHS called oral surgeons/surgical dentists to carry out bread-and-butter work that is part of the basic armamentarium of our GDPs. A dentist with a special interest in surgical dentistry/oral surgery appropriately remunerated is the most effective way to manage what are fundamentally out of hospital procedures. Most dentoalveolar waiting lists have been created in hospitals largely because it does not pay GDPs on NHS tariffs to carry out the work. The new proposed NHS contract will aggravate this. For the more complex problems where a hospital is required the service is already staffed by consultants in oral and maxillofacial surgery.

M. Heliotis

London

doi: 10.1038/sj.bdj.4813381

\section{Level playing field}

Sir, in the past few months the media has focussed an enormous amount of attention on the problems facing the population at large with having access to proper, regular, reliable dental health care - and in particular with the fact that so many dental practices now expect their patients to 'go private' instead of treating them through the current NHS provisions.

If this is the case, it is crucial that dentists are fully aware of the regulations concerning the sale of insurance products. If dentists wish to display posters and brochures of dental insurance schemes in their practices they are at liberty to do so but must stop 
short of recommending any particular one to their patients.

What too few dentists realise is that even by encouraging their NHS patients (or any patients at all) to 'convert' or sign up to any particular insurance scheme they are potentially contravening Financial Services Authority (FSA) regulations. If they are operating their own insurance schemes they must make sure that their scheme is compliant with all FSA regulations and that they themselves are authorised and regulated by the FSA, which is the regulatory body for insurance intermediaries and insurers in the UK.

The FSA rules dictate that dentists cannot offer any advice on the merits of any dental insurance scheme or recommend any of them to a patient, unless they are authorised to do so. Similarly, dentists cannot accept any premium monies relating to these types of policies from patients and, if they are operating a cash-back scheme, none of this money can be allocated to insurance schemes of any kind.

Any scheme, no matter how small, is deemed to be an insurance product and falls under the rules of the FSA for compliance. Furthermore any scheme with an element of insurance involved in it is subject to the payment of Insurance Premium Tax (IPT).

My group of companies works with many regulated firms. It is in the interests of everybody to ensure a level playing field and adherence to the law.

\section{G. Dixon}

\section{Managing Director, Compliance Solutions} By email

doi: 10.1038/sj.bdj.4813382

\section{Rose-tinted academia}

Sir, it was with some amusement that I read the opinion paper by Professors Kay and 0'Brien on academic dentistry (BDJ 2006; 200: 73-74). It certainly paints a delightful picture of a Nirvana-like place for enquiring minds in Manchester; this bears no relation to the reality of any UK dental school, but fuels debate.

Life for a young academic is hard. First you have to juggle the competing pressures of an almost full-time consultant training pathway with teaching, administration and of course research. In practice this means that weekends are often sacrificed at a time when you ought to be with your family. You have to spend interminable hours writing grant applications which you know have little chance of being funded. In contrast to the assertions of Kay and O'Brien, this writing is always done without administrative support. Finally you have to establish your name in research, not easy, as this requires great effort and not a little luck.

I hope that Professors Kay and 0'Brien's paper does stimulate more young people to enter academic dentistry, but I have my doubts. The real reason young people are not entering this part of the profession is because they want a life outside of their profession.

The way to attract young academics into dental schools is to have clearly defined, properly funded training pathways. A young academic's research should be supported and mentored in an internationally acclaimed academic group, something that seldom happens. Clinical training should be done imaginatively and with due regard to the competing pressures on time. There should be little teaching pressure for the first few years, rather than the common practice of 'dumping' courses on the most vulnerable. In short these valued young colleagues should be nurtured, protected and not used as workhorses.

I sincerely hope that Professors Kay and 0'Brien have taken off their roseate-tinted spectacles and are in the process of creating attractive realistic jobs for young academics in Manchester. If they have done this there will be the sound of the thunder of feet to Manchester and their recruiting problem will be over.

Academic dentistry is not in a good state in the UK and pretending it is something it is not doesn't help to rectify the problem.

\section{V. Martin}

Liverpool

doi: $10.1038 /$ sj.bdj.4813383

\section{A longstanding problem}

Sir, Kay and O'Brien (BDJ 2006; 200: 73-74)

paint a rosy view of dental academic life.

This may be the case in Manchester, but

elsewhere UK academic posts are not supported to the same extent. ${ }^{1}$ In orthodontics the national situation edges closer to collapse. From 40 full time academic posts in 1986 we now have just 28 and there are now only three lecturers in training posts. ${ }^{2}$ Were it not for the significant input from the NHS and support of our NHS colleagues, it is questionable whether the GDC would allow some courses to continue.

The Walport lecturers ${ }^{3}$ are the latest 'quickfix' for a longstanding problem which goes back to the era of industrial action taken by clinical academics in London in the late 1960s. The latest proposals are seen by the authors and the Council of Heads and Deans of Dental Schools ${ }^{4}$ as a way of remedying the general academic crisis in medicine and dentistry. This may be true but the difficulty will be when a lecturer attempts to obtain a Senior Academic Training Fellowship. First, the number of Fellowships (40 per year for the next five years) is not sufficient to reinvigorate all of academic medicine and dentistry. Secondly, half the funding for these posts must be provided by the local NHS Trust. ${ }^{5}$ Given the current problems of NHS funding I cannot see that many Trusts will be keen to enter into such five year funding agreements in support of academic dentistry.

Kay and 0'Brien state that: 'one of the great burdens placed on the clinical academic ... is the need to conduct research. I would have said, rather, that this was one of the few advantages of an academic career in dentistry. Sadly with funding for science being channelled towards larger groups, there are now few research groups within dental schools which are able to attract significant funding. This must now be added to the other six disadvantages of a career in academic dentistry listed by the Heads and Deans of dental schools. ${ }^{4}$

Any recent graduate contemplating an academic career in dentistry would be wise to ask themselves if these fundamental problems stand any chance of being adequately addressed in their professional lifetime. Sadly in mine they were not.

\section{D. Stephens OBE}

\section{Bristol}

1. Council of Head of Medical School and Council of Heads and Deans of Dental Schools. Clinical Academic staffing levels in UK Medical and Dental Schools: data update 2004. Appendix 8. June 2005 http://www.chms.ac.uk/ publications_and_guidance/index.htm

2. Benson P. The academic life. Editorial. J Orthod 2005; 32:227.

3. Academic sub-committee of UK Clinical Research Collaboration and Modernising Medical Careers. Medically and dentally qualified academic staff: Recommendations for training researchers and educators of the future (The Walport Report) http://www.ukcrc.org/pdf/Medically_and_Dentallyqualified_Academic_Staff_Report.pdf

4. Council of Heads of Medical School and Council of Heads and Deans of Dental Schools. Clinical Academic staffing levels in UK Medical and Dental Schools: data update 2004. p 16. June 2005. http://www.chms.ac.uk/ publications_and_guidance/index.htm

5. Higher Education Funding Council of England. Clinical Senior Lectureship Awards para 8. http://www.hefce.ac.uk/ research/cslaward/guidance.doc

doi: 10.1038/sj.bdj.4813384

\section{Ethical dilemma}

Sir, I wish to highlight the difficulty in obtaining ethical approval for research projects. This is an issue with which many clinicians and academics will identify. The application process involves two phases. Initially indemnity for the research is sought from the Research \& Development committee locally. Subsequent to obtaining local approval, permission is granted to apply centrally to the NHS Research Ethics Committee (REC). Unfortunately the local and central requirements for approval differ significantly. Application inevitably involves completion of the NHS REC application form comprising over 100 detailed questions covering areas from radioactive materials to complaints processes. Depending on the nature of the trial further requirements may include appropriately formatted CVs of principal researchers, letters of peer review, a 
letter from a statistician, consent forms for adult participants, assent forms for children, information sheets for adults, another for adolescents and another for younger children. Following submission of all the required material central approval usually takes three to four months. I fully appreciate the necessity to analyse research projects to facilitate high quality research and safeguard patient welfare, particularly in the case of trials of relatively new medicinal products. However, the majority of dental trials carry minimal risk. I feel the application process should be shortened and simplified, and the central application form made more relevant to dental research. Failure to address this issue may make clinicians in both primary and secondary settings less inclined to undertake research, rendering the evidence base on which we endeavour to base our patient care less robust and innovative. P. S. Fleming

London

doi: 10.1038/sj.bdj.4813385

\section{Missing the point}

Sir, I read with sadness the two letters $(B D J$ 2005; 199: 485) which appeared to ridicule the HealOzone and the review of Ozone The revolution in dentistry. I am relieved by, and fully support, the others who have also taken the opportunity to write to you with their feelings about these two letters.

The point seems to have been sadly missed that here is a twenty-first century treatment that is alien to 'drill n' fill' - something all dentists were taught historically as the only way to control and eradicate the infective process of dental decay. The dental profession now has the ability to detect decay long before cavitation has started, has an updated Clinical Severity Index to help guide them to the treatment of the lesion ${ }^{1}$ and the HealOzone to reverse these early lesions rapidly and predictably ${ }^{2}$ without the need for injections and drilling. ${ }^{3}$ Patients prefer this 'holistic' approach to their dental care. ${ }^{4,5}$ The entry of a patient into the cycle of drill and fill is irreversible. Once a hole is drilled into a tooth, the patient will always have it, and no matter how good a clinician each dentist perceives themselves to be, any restorative material will fail at some time.

The implications of this new technology are staggering. Not only is there clear financial gain to the health of the nation, ${ }^{6}$ there is a valid alternative to 'drill n' fill', and the many thousands of HealOzone users throughout the world cannot be wrong. Patients in these practices do not enter into the destructive cycle - and if a degree of preparation has to be carried out, then minimal tissue is destroyed, preserving the inherent tooth strength. ${ }^{7}$

In order to test opinion on ozone therapy among a group of 15 colleagues here in
South Africa, I contacted them informally earlier this year. All of the 15 feel the clinical use of the HealOzone to treat early caries is superior to conventional preventive methods. They all found that, based on their recall results in general practice, ozone and sealing was superior to conventional injecting, drilling and filling to manage occlusal caries with infected dentine extending up to $1 \mathrm{~mm}$ in depth. One hundred per cent of these dentists stated that ozone was superior to the conventional treatment of early root caries.

In fact, for 11 out of the 12 main uses of ozone in practice, there was at least 93\% agreement that the HealOzone was superior to conventional therapies. Lastly, not a single one of these dentists wanted to return to pre-HealOzone dental care, and all believed that this technology should be taught at dental schools around the world.

These data are part of a worldwide clinical audit currently in progress and while I realise that this does not represent a scientifically robust survey, surely one has to accept that there is something beneficial going on if such a number of respected, honest, clinically experienced colleagues are able to respond in such positive ways? If there really was nothing beneficial happening why would they persist? These dentists are working in the real world and have embraced change; they and their patients see the numerous benefits of this therapy compared to the conventional amputational therapies.

\section{J. Holmes \\ South Africa}

1. Holmes J, Lynch E. Clinical reversal of occlusal pit and fissure carious lesions (OPFCLs). IADR Abstract, 2003.

2. Holmes J. Clinical reversal of root caries using ozone, double-blind, randomised, controlled 18-month trial. Gerodonto/2003; 20: 106-114.

3. Baysan A, Lynch E. Management of root caries using ozone in vivo. J Dent Res 2001; 80:37.

4. Domingo $\mathrm{H}$ etal. Reducing barriers to care in patients managed with ozone. IADR, 2003

5. Megighian GD, Dal Vera M. Reducing barriers to care in patients managed with ozone in a general dental practice in Italy. IADR, Abstract 2003.

6. Domingo $\mathrm{H}$, Holmes $\mathrm{J}$ et al. Economic savings treating root caries with ozone or air abrasion. IADR, Abstract 2004.

7. Holmes J, Lynch E. Reversal of occlusal caries using air abrasion, ozone and sealing. IADR Abstract, 2004.

\section{doi: 10.1038/sj.bdj.4813386}

\section{Awarding degrees}

Sir, I was pleased to read the letter from Y. Maidment (BDJ 2006; 200: 125) contributing to developments in Scottish higher degrees. However Birmingham and not Edinburgh awarded the first higher dental degree. In 1901 it bestowed the postgraduate degree of Master of Dental Surgery on John Humphries, LDS (Ire) and Frank Earle Huxley, MRCS, LDS (Edin). I do not know if Edinburgh's DDS was the first such degree. 